\title{
Análise dos resíduos sólidos industriais perigosos no município de Panambi, RS
}

\author{
Analisys of dangerous industrial solid waste in the municipality of Panambi, RS
}

Fernanda Sampaio ${ }^{1}$ e Mauro Kumpfer Werlang ${ }^{2}$.

\begin{abstract}
${ }^{1}$ Mestre, Departamento de Geociências, Universidade Federal de Santa Maria, RS, Brasil; ${ }^{2}$ Doutor, Departamento de Geociências, Universidade Federal de Santa Maria, RS, Brasil. fernanda_rs1@hotmail.com; wermakwer@gmail.com
\end{abstract}

\begin{abstract}
Resumo
A pesquisa teve como objetivo identificar a quantidade e tipos de resíduos sólidos industriais gerados em 2010, nas indústrias do setor metal mecânico; investigar e caracterizar o acondicionamento, armazenamento, transporte, destinação final dos resíduos e, verificar a existência de programas de gerenciamento de resíduos e de educação ambiental. Os procedimentos utilizados foram entrevistas, análise documental de planilhas do Sistema de Gerenciamento e Controle de Resíduos Sólidos Industriais-SIGECORS enviadas à FEPAM (Fundação Estadual de Proteção Ambiental). Os principais resíduos gerados são o lodo perigoso, resíduos têxteis contaminados e outros resíduos perigosos de processo. Com exceção de apenas um tipo de resíduo, os demais são enviados para tratamento final em empresas recicladoras. Em relação ao transporte desses resíduos sólidos perigosos, uma indústria utiliza-se de maneira incorreta no transporte para envio à destinação final do resíduo. Duas das indústrias oferecem atividades de educação ambiental, as demais, apenas normas de conduta dentro da empresa e o Plano de Gerenciamento de Resíduos Sólidos está sendo elaborado em duas indústrias pesquisadas.
\end{abstract}

Palavras-chave: Indústria; Meio Ambiente; Gerenciamento de Resíduos Sólidos

\begin{abstract}
The research aimed to identify the amount and types of industrial solid waste produced in 2010, in the metalmechanical industries of the municipality; investigate and characterize the packaging, storage, transport, final destination of the waste and to verify the existence of waste management and environmental education programs. The procedures used were interviews, documental analisys from the spreadsheets from the Management and Control of Industrial Solid Waste System, SIGECORS, sended to FEPAM (Ambiental Protection State Foundation). The main aste generated are the dangerous sludge, textile contaminated waste and other proccess dangerous waste. Apart only one kind of waste, the others are sent to final treatment in recycling companies. With regard to the transport of these dangerous solid waste, one industry uses incorrect way in the transport to send to the final destination of the waste. Two industries offer environmental education activities, the others, only standart conduct in the company and the Solid Waste Management Plan is being developed in two researched industries.
\end{abstract}

Keywords: Industry; Environment; Solid Waste Management 


\section{Introdução}

O crescimento das cidades e o processo de industrialização têm influenciado significativamente o espaço urbano. O setor industrial foi um importante promotor de grandes transformações urbanas e também da multiplicação de diversos ramos de serviços que caracterizam a cidade moderna. Ele também acabou promovendo o desenvolvimento dos meios de transporte e comunicação. Além disso, contribuiu para o aumento da produtividade e para a elevação da produção agrícola. Tudo isso contribuiu para um novo modo de vida e outros hábitos de consumo, fazendo surgir novas profissões, estratificação da sociedade e uma outra perspectiva de relação com a natureza.

Nas últimas décadas houve incremento na produção e no consumo de bens industrializados e, aliado a isso, avançou também o risco dos resíduos sólidos industriais causarem implicações negativas para o meio ambiente, em diferentes graus e escalas.

Para que se possa reduzir a geração de resíduos sólidos industriais e os riscos que eles podem oferecer, é preciso que haja adequada gestão durante o processo produtivo. Uma alternativa está em usar material que ofereça facilidade para ser reciclado. De acordo com o artigo $2^{\circ}$ da Resolução n⿳ำ 307/2002 do CONAMA (Conselho Nacional do Meio Ambiente) "o gerenciamento de resíduos é o sistema de gestão que visa reduzir, reutilizar ou reciclar resíduos, incluindo planejamento, responsabilidades, práticas, procedimentos e recursos para desenvolver e implementar as ações necessárias ao cumprimento das etapas previstas em programas e planos".

No contexto dessa resolução, em relação à geração de resíduos sólidos industriais, encontra-se inserido o município de Panambi. Ele localiza-se no noroeste do Rio Grande do Sul e possui uma população de 38.058 habitantes (IBGE, 2010). Destaca-se, no âmbito do Estado, como a "cidade das máquinas" devido ao seu significativo número de indústrias. O setor metal mecânico do Município emprega mais de oito mil trabalhadores e responde por mais da metade PIB (Produto Interno Bruto) do Município e transforma, em média, cerca de 10.000 toneladas/mês de metais nesse setor. O Município possui várias indústrias de pequeno, médio e grande porte, em diversos ramos industriais, como metalúrgicas, metal mecânico, eletroeletrônica, malharias, moveleiro e produtos alimentícios. De acordo com Guarienti (2008) Panambi é conhecido como o terceiro pólo industrial metal-mecânico do Rio Grande do Sul. Em primeiro está Porto Alegre e, em segundo, Caxias do Sul.

Investigar a destinação final dos resíduos sólidos industriais perigosos no município de Panambi converge com a necessária compreensão dos danos que esses resíduos podem causar à saúde e ao meio ambiente, além de contribuir com o levantamento sistematizado de informações acerca dessatemática. No âmbito social, conforme esclarece Guarienti (2008), pesquisas nesse sentido contribuem para reflexões com relação à importância de como manusear e descartar os resíduos industriais perigosos. Assim, o trabalho tem como objetivo caracterizar a destinação final dos resíduos sólidos industriais perigosos do setor metal mecânico produzidos no município de Panambi, identificando espécies e quantidades, além de verificar a existência de programas de gerenciamento de resíduos e de educação ambiental para a conscientização da comunidade nas indústrias do setor metal mecânico do Município.

\section{Metodologia}

O método constitui a teoria da investigação para alcançar seus objetivos de forma científica, quando cumpre ou se propõe a cumprir as etapas necessárias à investigação.

Lakatos; Marconi, (2010, p.65) definem método como "conjunto das atividades sistemáticas e racionais que, com maior segurança e economia, permite alcançar o objetivo - conhecimentos válidos e verdadeiros - traçando o caminho a ser seguido, detectando erros e auxiliando as decisões do cientista". A fim de atender os objetivos estabelecidos para a pesquisa, optou-se pela utilização do método dedutivo, pois ele permite explicar o conteúdo das premissas. Conforme Lakatos; Marconi (2010, p.74), "os argumentos dedutivos ou estão corretos ou incorretos, ou as premissas sustentam de modo completo a conclusão ou, quando a forma é logicamente incorreta, não sustentam de forma alguma; portanto, não há graduações intermediárias".

A pesquisa foi realizada a partir de procedimentos que consistiram em levantamento bibliográfico, entrevistas e análise documental a partir de planilhas do Sistema de Gerenciamento e Controle de Resíduos Sólidos Industriais-SIGECORS enviados trimestralmente à FEPAM (Fundação Estadual de Proteção Ambiental) ou para a Prefeitura Municipal.

Com relação à análise documental, Lüdke; Menga (1986) argumentam que o uso de documentos possui uma série de vantagens durante a pesquisa. Uma delas se dá pela estabilidade e naturalidade das informações, pois o documento pode ser consultado sempre que necessário. Outra vantagem apresentada é o custo. Os autores apresentam três tipos de documentos: oficial (decreto, parecer), técnico (relatório, planejamento) e pessoal (uma carta, autobiografia). Observam que a escolha do documento depende do objetivo e dos propósitos de interesse do pesquisador. Destacam que uma vez escolhido os documentos, o próximo passo é analisar o que foi selecionado. Apresentam a definição proposta por Krippendorff (1980) em que o processo de análise de conteúdo inicia-se com a decisão da unidade de análise. Ainda Lüdke; Menga (1986) apresentam os dois tipos de análise, citados por Holsti (1969) que são as unidades de registro, onde o pesquisador pode selecionar dados 
Quadro 1 - Classificação das indústrias quanto ao porte

\begin{tabular}{|c|c|c|c|c|c|c|}
\hline \multirow{2}{*}{$\begin{array}{c}\text { Potencial } \\
\text { Poluidor }\end{array}$} & \multirow{2}{*}{$\begin{array}{c}\text { Unidade de } \\
\text { medida }\end{array}$} & Mínimo & Pequeno & Médio & Grande & Excepcional \\
\cline { 3 - 7 } & & Até 250 & $\begin{array}{c}250,01 \\
\text { Até } \\
2.000\end{array}$ & $\begin{array}{c}2.000,01 \text { até } \\
10.000\end{array}$ & $\begin{array}{c}10.000,01 \\
\text { até } 40.000\end{array}$ & Demais \\
\hline $\begin{array}{c}\text { Pequeno, médio } \\
\text { ou alto. }\end{array}$ & $\begin{array}{c}\text { Área útil em } \\
\mathrm{m}^{2}\end{array}$ & & & & \\
\hline
\end{tabular}

Fonte: Adaptado de FEPAM (2010).

específicos para analisar, e a da contextualização de uma determinada unidade ao invés de analisar sua freqüência.

Lüdke; Menga (1986) apontam duas maneiras de registrar os dados obtidos através da entrevista: a entrevista gravada e a anotação. A entrevista é uma das principais técnicas de trabalho utilizada nas ciências sociais. A grande vantagem de utilizá-la é que ela possibilita uma interação entre o pesquisador e o pesquisado. Outra vantagem da entrevista como tipo de metodologia de coleta de dados, é que durante ela é possível analisar, além das respostas, os sinais não verbais que são muito importantes para perceber a validade das informações respondidas pelo entrevistado.

A Resolução nº 102, de 24 de maio de 2005 do Conselho Estadual do Meio Ambiente (CONSEMA), é que autoriza ao órgão ambiental municipal, o licenciamento de empreendimentos com impacto local, caracterizado pelo porte da empresa, atividade e potencial poluidor. Caracteriza critério para a atividade de indústria de metalúrgica básica-fabricação de estrutura metálica sem tratamento de superfície e com pintura (exceto a pincel), potencial poluidor médio. Também é ela que dispõe ao município licenciar indústrias com área útil de até $2.000 \mathrm{~m}^{2}$.

Para a presente pesquisa, foi considerada a classificação das indústrias quanto ao porte para valores das taxas de licenciamento ambiental, conforme o quadro 1.

Para o levantamento das informações, precedeu-se um contato com a ACI (Associação Comercial e Industrial) do município de Panambi a fim de obter informações sobre as empresas que atuam no setor. A partir da listagem das indústrias do setor metal-mecânico associadas na ACI, foi realizado um contato telefônico com cada uma das empresas, para agendamento de entrevista com o responsável pelo setor do meio ambiente ou pessoa responsável pela documentação ambiental da empresa. Do conjunto de indústrias do setor metal mecânico associadas, seis delas aceitaram em contribuir com a pesquisa. A partir de então foi realizada uma breve apresentação do plano da pesquisa e de seus objetivos. Também foi apresentado um termo de consentimento informando que os dados e informações teriam exclusivo objetivo destinado à pesquisa. Foi aplicado, em cada uma das indústrias, um questionário com perguntas abertas sob forma de entrevista. Alguns outros dados, sobretudo os quantitativos, foram obtidos por correio eletrônico. Também foi visitada a área de armazenagem dos resíduos, instalações e o processo produtivo das indústrias sendo em apenas uma empresa foi permitido registro fotográfico.

Foi elaborado um cartograma representando a localização das indústrias no perímetro urbano de Panambi. Para representar graficamente para onde se destinam os resíduos sólidos perigosos, para receberem tratamento conforme legislação específica de acordo com cada tipo de resíduo, também foi elaborado um cartograma. Nele estão assinalados os municípios para onde sendo envia

dos os resíduos da indústria do setor metal mecânico de Panambi. Segundo Martinelli (2006) o cartograma representa uma representação e explica que para organizá -lo necessita-se dos dados que significam as quantidades deslocadas e uma base cartográfica, com o registro e identificação dos pontos de partida e chegada. O mapa resulta em uma articulação da informação, numa escala de representação.

\section{Resultados e discussão}

Observou-se que entre os diversos tipos de resíduos, o lodo, os panos e estopas constituem os maiores volumes gerados. Entretanto, é importante observar sob uma perspectiva da quantidade de resíduos produzidos, uma vez que esses apresentam diferentes potenciais poluidores. A tabela 1 mostra a quantificação dos dados dos resíduos gerados nas indústrias pesquisadas e, a figura 1, mostra a localização das indústrias por bairro, no perímetro urbano de Panambi.

No intuito de manter o anonimato das indústrias pesquisadas, foi estabelecido que estas fossem intituladas como empresa A, B, C, D, E F durante a apresentação e discussão dos resultados.

\section{Indústria A}

A “indústria A" está no mercado metal mecânico desde 2005. É de porte pequeno, e produz equipamentos para beneficiamento de grãos. Também é prestadora de serviços para o setor do agronegócio. Em relação aos resíduos sólidos industriais perigosos gerados no processo produtivo, esses são destinados para receberem tratamento 
Tabela 1 - Município de Panambi, RS: quantificação dos resíduos gerados nas indústrias pesquisadas

\begin{tabular}{c|c}
\hline Tipo de resíduo & $\begin{array}{c}\text { Quantidade anual } \\
\text { quilogramas } \\
\text { toneladas (ton.), } \\
\text { unidades (un). })\end{array}$ \\
\hline Resíduos de Serviços de Saúde (material infectado, agulhas, \\
medicamentos). & $171,89 \mathrm{~kg}$ \\
\hline Lodo perigoso de ETE & 275,025 ton. \\
\hline Resíduo perigoso de varrição & 21,905 ton. \\
\hline Oleo lubrificante usado & 19,33 ton. \\
\hline Material contaminado com óleo & 10,525 ton. \\
\hline Oleo de corte e usinagem & 8,795 ton. \\
\hline Outros resíduos perigosos de processo (corrosivo, resinas, material & 765.470 un. \\
\hline contaminado). & 11,457 ton. \\
\hline Péstil contaminado (panos, estopas). & 66,645 ton. \\
\hline Sónetálicos & 235,54 ton. \\
\hline Acumuladores de energia (baterias, pilhas, assemelhados) & 43,985 ton. \\
\hline Lâmpadas fluorescentes (vapor de mercúrio ou sódio). & 1.596 un. \\
\hline Embalagens vazias contaminadas & 4.223 un. \\
\hline Resíduo de tintas e pigmentos & 6.161 un. \\
\hline Resíduo e lodo de tinta & 32,2 ton. \\
\hline
\end{tabular}

Fonte: resultados obtidos durante a pesquisa.

numa empresa terceirizada contratada. A "indústria A" possui uma unidade de armazenamento temporário dos resíduos gerados no município de Panambi. Esses, posteriormente, são enviados para a unidade recicladora a fim de que seja realizado o tratamento adequado para cada tipo de resíduo. A indústria não possui controle sobre o quantitativo dos resíduos gerados. Eles não são pesados e a quantificação informada é baseada na capacidade dos tonéis nos quais os resíduos são acondicionados. $\mathrm{O}$ acondicionamento é feito em tonéis com capacidade de 200 litros, armazenados em local fechado e que, posteriormente são encaminhados para tratamento. O envio ocorre anualmente, frente à justificativa da quantidade gerada. Tanto os resíduos de tintas e pigmentos, quanto o óleo lubrificante passam pelo método de co-processamento que consiste na técnica de destruição térmica de resíduos em fornos de cimento. Nele, devido às altas temperaturas e ao tempo de residência, os resíduos são 100\% destruídos. Essa destruição térmica ocorre em fornos rotativos, sem emissão de gases poluentes à atmosfera e, após o procedimento é emitido um Certificado de Destruição Térmica.

\section{Indústria $B$}

A "indústria B" é considerada de porte médio e atua no setor metal mecânico há mais de 70 anos na fabricação de equipamentos industriais e domésticos que são conhecidos nacionalmente. Possui aproximadamente 50 funcionários e está licenciada pela FEPAM. Em relação ao controle dos resíduos sólidos industriais gerados no processo produtivo, esses são destinados para uma empresa contratada para tratamento e destino final.
Os resíduos são transportados com uma freqüência de quatro meses. Antes eles são acondicionados em tonéis metálicos e armazenados em local fechado com piso impermeabilizado. A vistoria pela FEPAM ocorre a cada dois anos e os arquivos relativos ao controle, enviados à FEPAM, são armazenados durante cinco anos. Em relação às atividades de educação ambiental, elas ocorrem com os funcionários que recebem orientações sobre esse tema. Para realizar o tratamento de co-processamento dos resíduos sólidos perigosos, a "indústria B" optou pela terceirização.

Os resíduos gerados na "indústria B", bem como suas quantidades, são: resíduo perigoso de varrição (1,5 ton.); material contaminado com óleo (2,5 toneladas); resíduo têxtil contaminado (1 tonelada) e lâmpadas fluorescentes (160 peças). No que se refere ao tratamento para as lâmpadas fluorescentes, essas são descontaminadas através do projeto "papa lâmpadas", composto por um tambor metálico com capacidade para 850 lâmpadas trituradas. Esse tambor possui um duplo sistema de filtragem, um para os fragmentos de vidro e pó fosfórico e outro para o vapor de mercúrio. O alumínio e o vidro triturados são encaminhados para outras empresas de reciclagem. Já o mercúrio, depositado no carvão, é posteriormente enviado para uma câmara de alta temperatura que através do calor, é novamente vaporizado, coletado e resfriado voltando à forma metálica original para ser reaproveitado em novas aplicações próprias do mercúrio. O carvão depois de liberado do mercúrio é depositado na natureza para ser decomposto. 


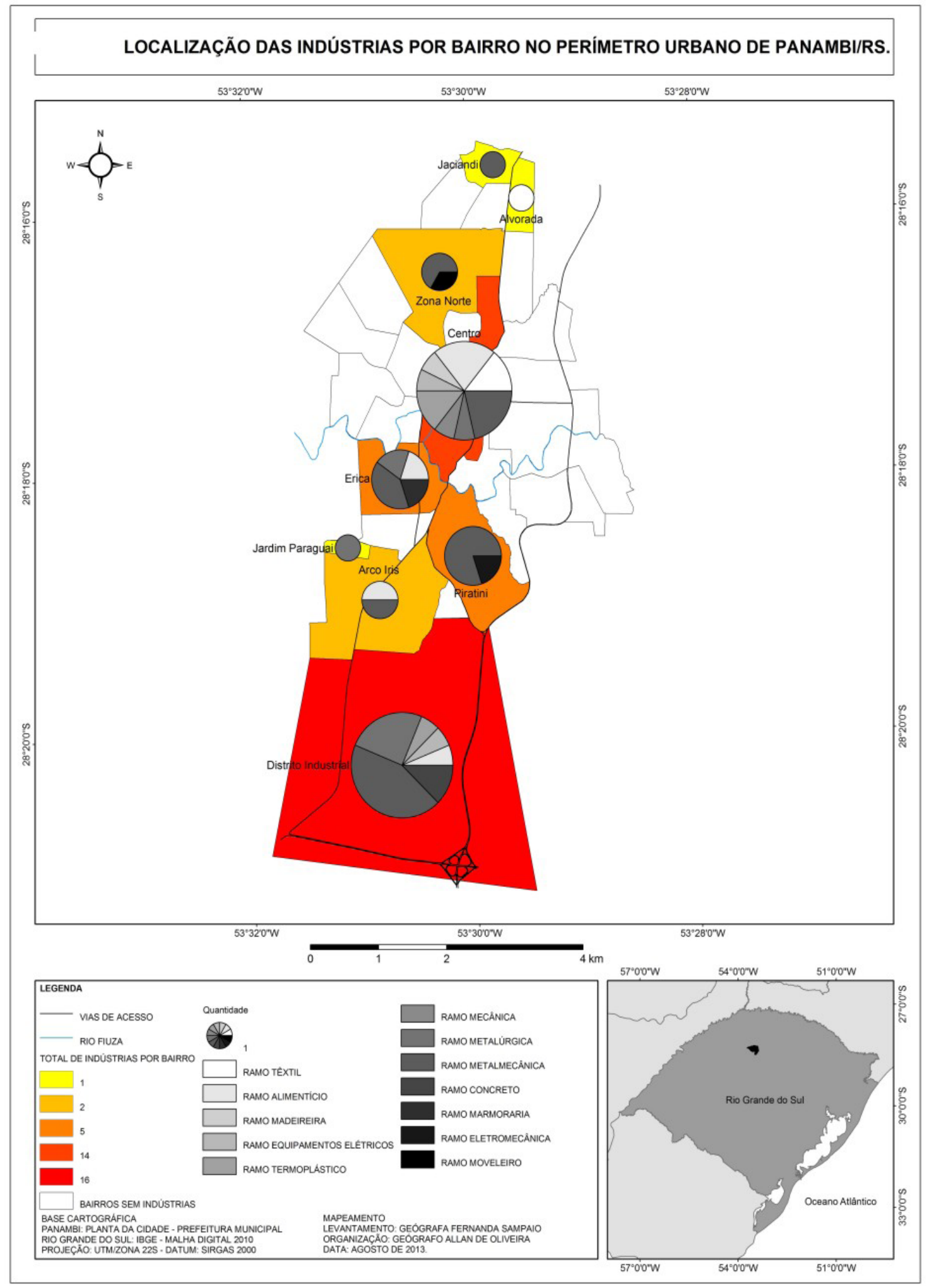

Figura 1 - Localização das indústrias no perímetro urbano de Panambi, RS Fonte: resultados obtidos durante a pesquisa.

\section{Indústria $\mathrm{C}$}

A “indústria C" atua no setor metal mecânico há seis anos em diversos segmentos como industrial, agroindustrial e automotivo. Possui licenciamento ambiental na
Prefeitura Municipal e é de porte pequeno. Os resíduos sólidos industriais perigosos gerados são acondicionados em tambores com capacidade para 200 litros que são armazenados na área de fabricação, em local fechado 
e coberto localizado no interior da indústria, uma vez que ela não dispõe de uma central de resíduos. A coleta dos resíduos, por parte de outra empresa recicladora terceirizada, é realizada com freqüência entre quatro e seis meses. Os tipos de resíduos e a quantidade gerada são: resíduos de equipamentos de proteção individual (60 kg); resíduo plástico contaminado $(40 \mathrm{~kg})$; material contaminado com óleo $(85 \mathrm{~kg})$ e resíduo têxtil como panos e estopas $(72 \mathrm{~kg})$.

\section{Indústria D}

A "indústria D" está a 66 anos no setor metal mecânico e é considerada de porte excepcional. Representa quase metade da renda do setor no município de Panambi empregando cerca de 3.200 funcionários, aproximadamente, $10 \%$ da população total do Município. A empresa está licenciada pela FEPAM desde 1995 para operação da atividade como de porte excepcional e autorização para remessa de Resíduos Sólidos Industriais classe I, para fora do Rio Grande do Sul. Possui certificações nas normas internacionais da Organização Internacional para Padronização (International Organization for Standardization) ISO 9001 e ISO 14001 que se referem a Sistemas de Gestão de Qualidade e a Sistemas de Gestão Ambiental, respectivamente. A empresa desenvolve atividades relacionadas com educação ambiental e, estas ocorrem através de programas em escolas no Município.

O controle de geração dos resíduos, na "indústria D" ocorre com a pesagem semanal, quando esses saem da Central de Resíduos e são enviados para o tratamento final. A empresa possui instrução ambiental separada para cada tipo de resíduo e o transporte de resíduos sólidos perigosos é realizado por caminhões terceirizados licenciados pela FEPAM. Em relação aos resíduos sólidos perigosos gerados pela empresa e tratados no próprio Município, são identificados dois tipos: solventes contaminados e os acumuladores de energia (baterias, pilhas e assemelhados). Para os solventes, o tratamento utilizado ocorre inicialmente com o processo de filtragem prévia para a retenção de sólidos que porventura estejam presentes. Em seguida, este é bombeado para um dos destiladores pré-definidos, onde passa por aumento de temperatura através da aplicação de vapor. Quando alcançado o ponto de ebulição, este material passa do estado líquido para o gasoso, separando-se assim de seu contaminante, que ficará retido no destilador. O gás do material destilado é transportado automaticamente a outro equipamento instalado em linha, denominado condensador, onde sofre um resfriamento abrupto que o faz retornar novamente ao seu estado líquido. Tem-se então, neste momento, praticamente em sua condição original, o solvente, que após passar por processo de reestabilização e rebalanceamento poderá ser reutilizado novamente. Já os resíduos de acumuladores de energia são entregues ao fornecedor, que o devolve ao fabricante. A tabela 2 mostra a quantificação dos resíduos gerados na "indústria D".

Ainda em relação à "indústria D", os resíduos de serviços de saúde são transportados e armazenados em outra cidade do Rio Grande do Sul, para posterior tratamento na empresa recicladora terceirizada localizada fora do Estado. Em relação ao resíduo óleo lubrificante, observa-se que ao chegar à unidade de destinação final para tratamento, ele é analisado pelo controle de qualidade e após a aprovação por parte deste setor, é filtrado e armazenado em tanques apropriados. Quanto ao processo de tratamento dos resíduos têxteis contaminados, no caso de uniformes, Equipamentos de Proteção Individual-EPI, toalhas industriais e outros, ocorrem com a lavagem e higienização. Basicamente são empregadas operações de lavagem, enxágüe centrifugação e secagem. Alguns EPIs passam por processos de lavagem a seco. Algumas toalhas industriais passam também, por processo de resinamento após a lavagem. Esses resíduos são destinados para tratamento em empresas terceirizadas. Em relação às embalagens vazias

Tabela 2 - Município de Panambi: quantificação anual dos resíduos gerados nas indústrias - indústria "D”

\begin{tabular}{|c|c|}
\hline Tipo de resíduo & $\begin{array}{l}\text { Quantidade anual quilogramas } \\
\text { (kg), toneladas (ton.), unidades } \\
\text { (un.) }\end{array}$ \\
\hline Resíduos de Serviços de Saúde (material infectado, agulhas, medicamentos). & $106,89 \mathrm{~kg}$ \\
\hline Lodo perigoso de ETE & 272,35 ton. \\
\hline Óleo lubrificante usado & 16,93 ton. \\
\hline Resíduo têxtil contaminado (panos, estopas). & 765.470 un. \\
\hline Solventes contaminados. & 32,58 ton. \\
\hline Outros resíduos perigosos de processo (corrosivo, resinas, material contaminado). & 209,405 ton. \\
\hline Pós metálicos & 33,04 ton. \\
\hline Acumuladores de energia (baterias, pilhas, assemelhados) & 1.517 un. \\
\hline Lâmpadas fluorescentes (vapor de mercúrio ou sódio) & 3.046 un. \\
\hline Embalagens vazias contaminadas & 6.161 un. \\
\hline Resíduo de tintas e pigmentos & 23,84 ton. \\
\hline Resíduo e lodo de tinta & 9,12 ton. \\
\hline
\end{tabular}


contaminadas, elas são encaminhadas para empresas recicladoras. Os resíduos de tintas e pigmentos e o resíduo e lodo de tinta, são tratados na própria indústria, para serem, posteriormente, reutilizados.

\section{Indústria $\mathrm{E}$}

A “indústria E" está no mercado há mais de 80 anos e, no setor metal mecânico está atuando a mais de 30 anos. Apresenta licenciamento ambiental pela FEPAM e é classificada como de porte excepcional. É considerada uma das principais e mais tradicionais indústrias do Município, tanto pelo tempo de existência quanto pela importância para a economia de Panambi.

Os dados da tabela 3 mostram a quantidade anual dos tipos de resíduos sólidos perigosos gerados no processo produtivo da indústria "E". O controle dos resíduos sólidos perigosos é realizado na Central de Resíduos da indústria. $\mathrm{Na}$ área do processo produtivo estão dispostos tonéis com capacidade de 200 litros, revestidos com sacos de alta densidade para descarte dos resíduos gerados. Esses, quando cheios, vãos para a Central de Resíduos da indústria para posterior tratamento em empresas terceirizadas, o que ocorre trimestralmente. Dos resíduos sólidos perigosos gerados na "indústria E", dois são tratados no Município: solventes contaminados e resíduos de tintas e pigmentos. Os demais são acondicionados na Central de Resíduos e, posteriormente encaminhados para tratamento em diferentes empresas localizadas em outros municípios e estados. Quanto às atividades relacionadas à educação ambiental, essas ocorrem por meio de programas de integração entre funcionários e a comunidade de Panambi.

Quanto ao tratamento dado aos resíduos sólidos perigosos gerados no processo produtivo da "indústria E", estes acontecem conforme o tipo de resíduo gerado. Para os de serviços de saúde, são transportados e arma- zenados em outra cidade do Rio Grande do Sul para posterior tratamento. Os resíduos sólidos perigosos de solventes contaminados e resíduos de tinta e pigmentos (tinta líquida) recebem tratamento no município de Panambi. Em relação às lâmpadas, elas são recolhidas e tratadas pela mesma empresa recicladora terceirizada que presta serviço para a indústria. Os resíduos de plástico contaminado são enviados a uma empresa especializada para descontaminação e reciclagem. Os resíduos de óleo lubrificante são encaminhados para tratamento de rerrefino conforme a Resolução CONAMA nº 362/2005. Em relação aos resíduos de tinta pastosa e sólida esses são destinados para incineração. A destinação dos resíduos de lodo perigoso da ETE e resíduo de óleo de corte e usinagem, bem como os outros resíduos perigosos do processo (adesivos, vedantes, etc), resíduos de papel e papelão contaminado, resíduo perigoso de varrição e resíduo têxtil contaminado, é o co-processamento. Quanto aos resíduos de pós-metálicos, assim como os resíduos de acumuladores de energia (baterias, pilhas, assemelhados) a destinação final também é realizada pela empresa terceirizada.

\section{Indústria $\mathrm{F}$}

A "indústria F" caracteriza-se como de pequeno porte. É licenciada pela Prefeitura Municipal e instalada no Distrito Industrial atuando a mais de 10 anos no setor metal mecânico de Panambi.

Os resíduos sólidos perigosos gerados são controlados através de pesagem semanal e armazenados em tonéis com capacidade de 200 litros e acondicionados na Central de Resíduos da indústria. A quantidade de resíduos sólidos perigosos gerados é: 0,459 tonelada de resíduo têxtil contaminado e 0,459 tonelada de resíduo de tintas e pigmentos.

Quanto ao transporte desses resíduos sólidos perigo-

Tabela 3 - Município de Panambi: quantificação anual dos resíduos gerados nas indústrias - indústria “E”

\begin{tabular}{|c|c|}
\hline Tipo de resíduo & $\begin{array}{l}\text { Quantidade anual quilogramas } \\
\text { (kg), toneladas (ton.), unidades } \\
\text { (un).) }\end{array}$ \\
\hline Resíduos de Serviços de Saúde (material infectado, agulhas, medicamentos). & 0,065 ton. \\
\hline Lodo perigoso de ETE & 2,675 ton. \\
\hline Resíduo perigoso de varrição & 20,405 ton. \\
\hline Óleo lubrificante usado & 1,4 ton. \\
\hline Material contaminado com óleo - papel e papelão contaminado & 7,9 ton. \\
\hline Óleo de corte e usinagem & 8,795 ton. \\
\hline Resíduo têxtil contaminado (panos, estopas). & 9,925 ton. \\
\hline Solventes contaminados & 23,985 ton. \\
\hline Outros resíduos perigosos de processo (adesivos, vedantes, etc.) & 26,135 ton. \\
\hline Pós metálicos & 7,59 ton. \\
\hline Acumuladores de energia (baterias, pilhas, assemelhados) & 79 un. \\
\hline Lâmpadas fluorescentes (vapor de mercúrio ou sódio) & 1.017 un. \\
\hline Resíduo de tintas e pigmentos & 6,86 ton. \\
\hline Resíduo e lodo de tinta & 61,455 ton. \\
\hline
\end{tabular}

Fonte: resultados obtidos durante a pesquisa. 


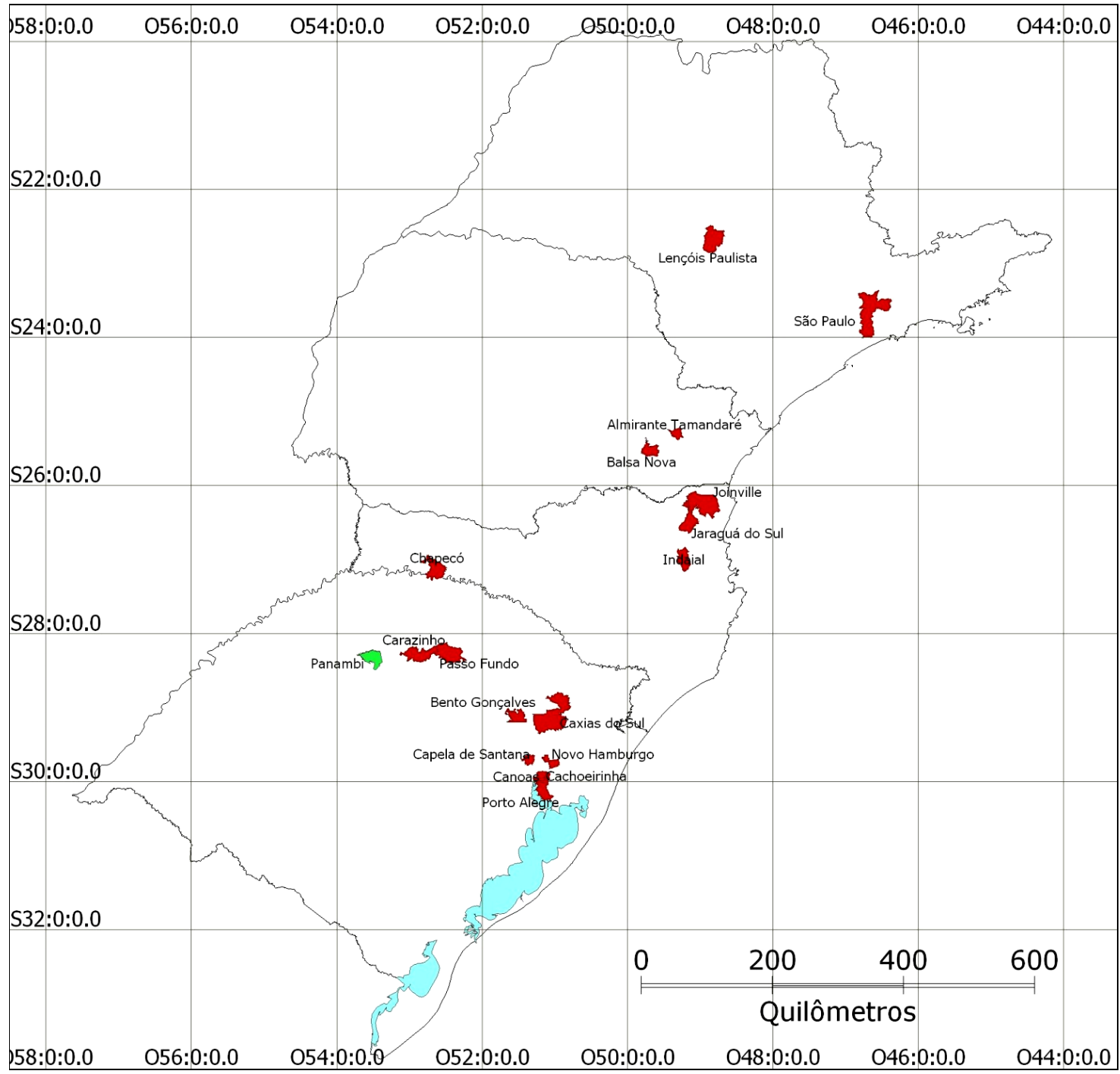

Figura 2 - Destinação final dos resíduos sólidos perigosos produzidos no município de Panambi, RS Fonte: resultados obtidos durante a pesquisa.

sos gerados eles são encaminhados semanalmente com veículo próprio da empresa até o local destinado pela empresa recicladora terceirizada para posterior remoção e tratamento. Com relação às atividades de educação ambiental, são realizadas na empresa atividades com os funcionários como norma de conduta.

\section{Destinação final dos resíduos sólidos perigosos produzidos no município de Panambi}

A partir das informações obtidas nas indústrias pesquisadas foi possível constatar que, em relação à destinação final dos resíduos sólidos perigosos gerados, as indústrias A, B, C e F destinam seus resíduos para coprocessamento. A quantidade de resíduos gerados é compatível com o porte dessas indústrias. Os tipos de resíduos gerados, considerados perigosos, são condizentes com a atividade das indústrias pesquisadas, porém, são distintos em cada uma delas em face da natureza de sua atividade.

Quanto aos programas de educação ambiental, as indústrias $\mathrm{A}$ e $\mathrm{C}$ declararam que não realizam nenhuma atividade relacionada a esse tema. Já as indústrias B e $\mathrm{F}$, relataram que desenvolvem atividades apenas com os seus funcionários.

Nas indústrias D e E, devido ao volume de resíduos gerados, a destinação final ocorre para mais de uma empresa recicladora terceirizada. Constata-se que alguns resíduos são tratados no próprio Município. Essa atitude se dá em função da busca pela redução de custos da empresa com o transporte desses resíduos. A figura 2 mostra o cartograma obtido, indicando a destinação final dos resíduos sólidos perigosos produzidos no município de Panambi. Observa-se que ela ocorre, além do Rio Grande do Sul, nos estados de Santa Catarina, Paraná e São Paulo. 
Os resultados permitem observar que entre os principais resíduos sólidos industriais nas indústrias do setor metal mecânico do município de Panambi, está o lodo perigoso de ETE, os resíduos têxteis contaminados além de outros resíduos perigosos de processo, resíduos de serviços de saúde, resíduo perigoso de varrição, resíduo perigoso de varrição, óleo lubrificante usado, material contaminado com óleo - papel e papelão contaminado, óleo de corte e usinagem, solventes contaminados, resíduos pós metálicos, acumuladores de energia, lâmpadas fluorescentes, resíduo de tintas e pigmentos, resíduo e lodo de tinta. Com exceção de apenas um tipo de resíduo sólido industrial gerado no Município, que fica armazenado na central de resíduos de uma empresa, os demais resíduos das indústrias pesquisadas no setor metal mecânico no Município são enviados para tratamento final em empresas recicladoras nos estados do Rio Grande do Sul, Santa Catarina, Paraná e São Paulo. No que se refere aos programas de educação ambiental, duas das indústrias pesquisadas realizam atividades para esse fim, as demais oferecem apenas normas de conduta dentro da empresa.

\section{Conclusões}

Os principais resíduos gerados no setor metal mecânico de Panambi são o lodo perigoso de ETE, os resíduos têxteis contaminados e solventes. Há também uma série de outros resíduos perigosos de processo gerados nessas indústrias. Com exceção de apenas um tipo de resíduo, os demais são enviados para tratamento final em empresas recicladoras terceirizadas. Em relação ao transporte desses resíduos perigosos, detectou-se que uma indústria faz uso inadequado de transporte para envio à destinação final para o resíduo. Duas das indústrias oferecem atividades de educação ambiental, as demais, apenas normas de conduta dentro da empresa e o Plano de Gerenciamento de Resíduos Sólidos está sendo elaborado em duas indústrias pesquisadas. A destinação final dos resíduos perigosos produzidos no município de Panambi ocorre, além do Rio Grande do Sul, nos estados de Santa Catarina, Paraná e São Paulo.

\section{Referências}

INSTITUTO BRASILEIRO DE GEOGRAFIA E ESTATÍSTICA-IBGE. Disponível em <http://www.ibge. gov.br. Acesso em: 10 ago. 2013.

INSTITUTO BRASILEIRO DE GEOGRAFIA E ESTATÍSTICA - IBGE. CIDADES: Rio Grande do Sul. Disponível em <http://www.ibge.gov.br/cidadesat Acesso em: 23 out. 2010.

FUNDAÇÃO ESTADUAL DE PROTEÇÃO AMBIENTAL
- FEPAM. Disponível em <http://www.fepam.rs.gov.br/ Acesso em: 23 out. 2010.

GUARIENTI, A. (2008). Perspectivas do setor metalmecânico na região de Panambi, RS. Dissertação (Mestrado em Engenharia de Produção) - Programa de Pós-Graduação em Engenharia de Produção, Universidade Federal de Santa Maria, Santa Maria.

LÜDKE, M.; ANDRÉ, M. (1986) Pesquisa em educação: abordagens qualitativas. EPU: São Paulo.

LAKATOS, E. M., MARCONI, M. A. (2010) Fundamentos de metodologia científica. 7.ed. Atlas: São Paulo.

MARTINELLI, Marcello. (2006) Mapas da geografia e cartografia temática. 3.ed. Contexto: São Paulo.

MINISTÉRIO DO MEIO AMBIENTE. Conselho Nacional do Meio Ambiente - CONAMA. Resolução nº 307, de 05 de julho de 2002. Estabelece diretrizes, critérios e procedimentos para a gestão dos resíduos da construção civil. Disponível em http://www.mma.gov.br/port/ conama Acesso em: 19 jun.2011. 